\title{
ANALISIS INDEKS STABILITAS SISA PADA CAMPURAN ASPHALT CONCRETE DENGAN PENGGUNAAN LIMBAH PLASTIK SEBAGAI AGREGAT PENGGANTI
}

\author{
Anissa Noor Tajudin ${ }^{1}$ dan Latif Budi Suparma ${ }^{2}$ \\ ${ }^{1}$ Jurusan Teknik Sipil, Universitas Tarumanagara Jakarta \\ nissatajudin@yahoo.com \\ ${ }^{2}$ Departemen Teknik Sipil dan Lingkungan, Universitas Gadjah Mada Yogyakarta \\ lbsuparma@mstt.ugm.ac.id
}

\begin{abstract}
ABSTRAK
Sulitnya penguraian limbah plastik seharusnya menjadi pemacu untuk mengolah kembali limbah tersebut menjadi sesuatu yang bermanfaat, sehingga kualitas lingkungan terjaga dan limbah plastik memiliki nilai fungsi. Selain itu, curah hujan tinggi sering mengakibatkan genangan pada permukaan jalan yang dapat menurunkan keawetan jalan. Inovasi dalam perancangan perkerasan jalan perlu terus dilakukan agar didapat kualitas perkerasan yang mampu bertahan pada cuaca ekstrim. Penelitian ini dilakukan untuk mengetahui pengaruh air terhadap stabilitas campuran panas Asphalt Concrete - Binder Course $(A C-B C)$ dengan penggunaan biji limbah plastik High Density Polyethylene (HDPE) sebagai agregat pengganti. Variasi biji limbah plastik yang digunakan adalah sebesar 0\%, $25 \%$, dan $50 \%$ terhadap volume agregat yang lolos saringan no. 4 dan tertahan saringan no. 8. Pelaksanaan penelitian terdiri dari pemeriksaan karakteristik bahan dan campuran aspal panas $A C-B C$, perancangan gradasi agregat, perancangan variasi plastik dan gradasi baru campuran, pengujian rendaman standar, pengujian rendaman modifikasi, dan analisa stabilitas yang dilakukan pada perendaman selama 30 menit, 1 hari, 2 hari, 4 hari, dan 7 hari. Hasil analisis Indeks Stabilitas Sisa (IRS) menunjukkan campuran dengan variasi plastik 25\% mengalami kehilangan kekuatan yang paling sedikit, atau dengan kata lain campuran tersebut lebih tahan terhadap pengaruh air dibandingkan dengan variasi plastik lainnya. Tingginya kekuatan campuran dengan variasi plastik $25 \%$ ditunjukkan dengan nilai Indeks IRS yang paling tinggi diantara variasi lainnya, yaitu sebesar $76,10 \%$ pada akhir masa perendaman selama 7 hari. Hanya campuran dengan variasi plastik 25\% ini yang memenuhi persyaratan minimum IRS 75\%.
\end{abstract}

Kata kunci: AC-BC, limbah plastik, stabilitas, indeks stabilitas sisa

\section{PENDAHULUAN}

Di seluruh dunia, produksi plastik cenderung mengalami peningkatan dari tahun ke tahun. Pada tahun 2012, produksi plastik meningkat sebesar 288 juta ton atau 2,8\% lebih besar dari tahun sebelumnya (PlasticEurope, 2013). Plastik sebagai bahan yang tidak biodegradable tentunya akan menimbulkan permasalahan tersendiri. Sulitnya proses penguraian limbah plastik seharusnya memacu pola pikir masyarakat untuk mengolah kembali limbah tersebut menjadi sesuatu yang bermanfaat, sehingga kualitas lingkungan terjaga dan limbah plastik memiliki nilai fungsi. Selain itu, curah hujan tinggi sering mengakibatkan genangan pada permukaan jalan yang dapat menurunkan keawetan jalan. Inovasi dalam perancangan perkerasan jalan perlu terus dilakukan agar didapat kualitas perkerasan yang mampu bertahan pada cuaca yang ekstrim. (Tajudin, 2015)

Pokok permasalahan yang akan didalami melalui penelitian ini adalah analisis Indeks Stabilitas Sisa (IRS) pada campuran Asphalt Concrete - Binder Course (AC - BC) dengan penggunaan biji limbah plastik High Density Polyethylene (HDPE) sebagai agregat pengganti pada campuran panas gradasi rapat apabila campuran direndam dengan rentang waktu 30 menit, 1 hari, 2 hari, 4 hari, dan 7 hari. Variasi biji limbah plastik yang digunakan adalah sebesar $0 \%, 25 \%$, dan $50 \%$ terhadap volume agregat yang lolos saringan no. 4 dan tertahan no. 8 . 
Penelitian ini diharapkan dapat memberikan gambaran mengenai kekuatan campuran terhadap pengaruh air. Penelitian ini juga diharapkan dapat memberikan alternatif optimalisasi pengolahan limbah plastik, sehingga penipisan sumber daya dan degradasi lingkungan dapat diminimalisir.

Asphalt Concrete - Binder Course (AC-BC) disebut juga lapis antara karena letaknya yang berada di antara lapis aus dan lapis pondasi (Sutaryo, 2004). Spesifikasi Umum Perkerasan Jalan menetapkan gradasi kasar dan halus untuk campuran AC-BC. Agregat bergdradasi kasar dapat digunakan pada daerah yang mengalami deformasi tinggi seperti pada gerbang tol, daerah pegunungan, dan pada daerah dekat lampu merah (Sumiati dan Sukarman, 2014).

Stabilitas merupakan salah satu karakteristik campuran beraspal yang kekuatannya harus memenuhi syarat spesifikasi agar didapatkan campuran yang efektif dan kuat. Dalam Asphalt Institute (2001), stabilitas adalah kemampuan campuran untuk melawan deformasi atau perubahan bentuk yang disebabkan oleh lalu-lintas yang harus dipikul. Stabilitas tergantung dari gaya gesek (internal friction) dan kohesi (cohesion), sedangkan internal friction tergantung pada surface texture, gradasi agregat, bentuk kombinasi dari gaya gesek dan kemampuan saling mengunci dari agregat pada campuran. Tahan gesek akan bertambah seiring dengan bertambahnya kekerasan dan area permukaan kontak agregat. Indeks Stabilitas Sisa (IRS) merupakan perbandingan stabilitas campuran yang direndam dengan stabilitas standar yang dinyatakan dalam persen. Angka IRS menunjukkan besarnya stabilitas yang masih dimiliki oleh campuran setelah dipengaruhi oleh air dari perendaman dengan lama waktu tertentu.

Yilmaz dan Sargin (2012) dalam penelitiannya menyebutkan pengaruh air terhadap kerusakan perkerasan merupakan suatu hal yang kompleks dan berhubungan dengan thermodinamik, kimiawi, fisik, dan proses mekanik. Hicks et al (2003) menyebutkan sifat kimia pada permukaan agregat dan ada atau tidaknya lempung halus merupakan faktor penting yang mempengaruhi adhesi antara agregat dan pengikat aspal. Aspal pengikat dapat mempengaruhi adhesi antar aspal dan agregat dan kohesi pada campuran. Adhesi dipengaruhi oleh sifat kimia dan kekakuan aspal. Kekuatan kohesi aspal terhadap pengaruh air juga dipengaruhi oleh sifat kimia dan teknik pengolahan aspal tersebut. Adhesi yang buruk akan menyebabkan stripping aspal dari permukaan agregat, sedangkan kohesi yang buruk akan menyebabkan hilangnya kekakuan campuran

High Density Polyethylene (HDPE) merupakan salah satu jenis plastik polietilen. HDPE merupakan jenis polietilen yang memiliki tingkat kerapatan tinggi, sehingga bahan ini tahan terhadap panas, dingin, air, cuaca, goresan, serta bahan isolator yang baik (Schwarz, 1986). Penggunaan limbah plastik dalam campuran aspal sudah banyak dilakukan, baik sebagai modifikasi aspal, pelapis agregat, atau sebagai pengganti agregat. Nejad et al (2013) membuktikan bahwa penggunaan plastik HDPE sebagai pelapis agregat memberikan kuat tarik dan ketahanan terhadap pengaruh air yang lebih besar dibandingkan dengan agregat tanpa pelapis atau agregat yang dilapisi jenis polietilen lain. Dalam penelitian yang dilakukan Tajudin dan Suparma (2014), plastik HDPE yang digunakan sebagai pengganti agregat terbukti memenuhi persyaratan volumetric dan stabilitas untuk perendaman standar, sehingga penelitian lebih lanjut untuk menguji kekuatan campuran perlu untuk dilaksanakan. 


\section{METODE PENELITIAN}

Pelaksanaan penelitian terdiri dari pemeriksaan karakteristik bahan dan campuran aspal panas AC-BC, perancangan gradasi agregat, perancangan variasi plastik dan gradasi baru campuran, pengujian rendaman standar, pengujian rendaman modifikasi, dan analisa stabilitas yang dilakukan pada perendaman selama 30 menit, 1 hari, 2 hari, 4 hari, dan 7 hari.

Peralatan penelitian yang digunakan antara lain peralatan untuk pemeriksaan sifat fisik aspal, sifat fisik agregat, sifat fisik biji limbah plastik, peralatan untuk pembuatan benda uji seperti timbangan, cetakan, alat pemadat, oven, thermometer, waterbath, serta peralatan uji Marshall untuk pengujian stabilitas.

\section{Pemeriksaan Karakteristik Bahan Campuran}

Pemeriksaan dilakukan terhadap agregat, filler, aspal, dan biji limbah plastik. Pemeriksaan dilakukan untuk mendapatkan bahan penyusun campuran yang memenuhi Spesifikasi Umum Direktorat Jendral Bina Marga Edisi 2010 Revisi 3 Divisi 6. Pemeriksaan dilakukan dengan mengacu pada prosedur SNI dan AASHTO. Bahan-bahan yang digunakan dalam penelitian ini antara lain:

a) Agregat kasar, halus dan filler berasal dari Clereng, Kulon Progo, DIY.

b) Aspal penetrasi 60/70 produksi PT. Pertamina.

c) Biji limbah plastik dengan ukuran butiran lolos saringan no. 4 dan tertahan no. 8. Biji limbah plastik ini diperoleh dari industri plastik PT. Inti Indah Plasindo, Solo.

\section{Perancangan Gradasi Agregat}

Gradasi agregat dapat dinyatakan dalam perbandingan terhadap berat atau perbandingan terhadap volume. Perbandingan terhadap berat dapat dilakukan jika selisih berat jenis agregat yang digunakan kurang dari 0,2 (Asphalt Institute, 2001). Di dalam penelitian ini menggunakan perbandingan volume karena selisih berat jenis agregat yang digunakan lebih dari 0,2. Rancangan dan komposisi agregat tercantum dalam Tabel 1.

Tabel 1. Rancangan gradasi dan komposisi agregat

\begin{tabular}{|c|c|c|c|c|c|c|c|c|}
\hline \multirow{3}{*}{ Bahan } & \multirow{2}{*}{\multicolumn{2}{|c|}{ Saringan }} & \multirow{2}{*}{\multicolumn{3}{|c|}{$\begin{array}{c}\text { Spesifikasi Lolos } \\
(\%)\end{array}$}} & \multirow{3}{*}{$\begin{array}{c}\text { Tinggal } \\
\text { Di Atas } \\
(\%) \\
\end{array}$} & \multirow{2}{*}{\multicolumn{2}{|c|}{$\begin{array}{c}\text { Jumlah Menurut } \\
\text { Spesifikasi }\end{array}$}} \\
\hline & & & & & & & & \\
\hline & $\mathrm{mm}$ & \# & Min & Maks & Target & & Tinggal (\%) & (gram) \\
\hline \multirow{6}{*}{$\begin{array}{l}\text { Agregat } \\
\text { Kasar } \\
57,48 \%\end{array}$} & 25,4 & $1 "$ & 100 & 100 & 100 & 0 & & \\
\hline & 19,1 & $3 / 4 "$ & 90 & 100 & 95 & 5 & 4,94 & 54 \\
\hline & 12,7 & $1 / 2^{\prime \prime}$ & 74 & 90 & 82 & 18 & 12,84 & 141 \\
\hline & 9,52 & $3 / 8^{\prime \prime}$ & 64 & 82 & 73 & 27 & 8,89 & 98 \\
\hline & 4,76 & $\# 4$ & 47 & 64 & 55,5 & 44,5 & 17,28 & 190 \\
\hline & 2,36 & $\# 8$ & 34,6 & 49 & 41,8 & 58,2 & 13,53 & 149 \\
\hline \multirow{5}{*}{$\begin{array}{l}\text { Agregat } \\
\text { Halus } \\
36,28 \%\end{array}$} & 1,18 & $\# 16$ & 28,3 & 38 & 33,15 & 66,85 & 8,77 & 96 \\
\hline & 0,59 & \#30 & 20,7 & 28 & 24,35 & 75,65 & 8,92 & 98 \\
\hline & 0,279 & $\# 50$ & 13,7 & 20 & 16,85 & 83,15 & 7,60 & 84 \\
\hline & 0,149 & \# 100 & 4 & 13 & 8,5 & 91,5 & 8,46 & 93 \\
\hline & 0,074 & \# 200 & 4 & 8 & 6 & 94 & 2,53 & 28 \\
\hline $\begin{array}{l}\text { Filler } \\
6,24 \%\end{array}$ & PAN & & & & & 100 & 6,24 & 69 \\
\hline
\end{tabular}




\section{Variasi Plastik dan Gradasi Baru Campuran}

Dalam penelitian ini variasi agregat lolos saringan no. 4 dan tertahan saringan No. 8 yang digantikan oleh limbah plastik adalah sebanyak 2 jenis, yaitu $25 \%$ dan $50 \%$ terhadap volume yang seharusnya ditempati agregat lolos saringan no. 4 dan tertahan saringan No. 8. (Gambar 1). Kadar aspal optimum yang digunakan pada masing-masing variasi limbah plastik dalam campuran tercantum pada Tabel 2.

Tabel 2. Kadar aspal optimum campuran AC-BC

\begin{tabular}{cc}
\hline Variasi Limbah Plastik & Kadar Aspal Optimum (KAO) \\
\hline $0 \%$ & $6 \%$ \\
$25 \%$ & $6,3 \%$ \\
$50 \%$ & $7,1 \%$ \\
\hline
\end{tabular}

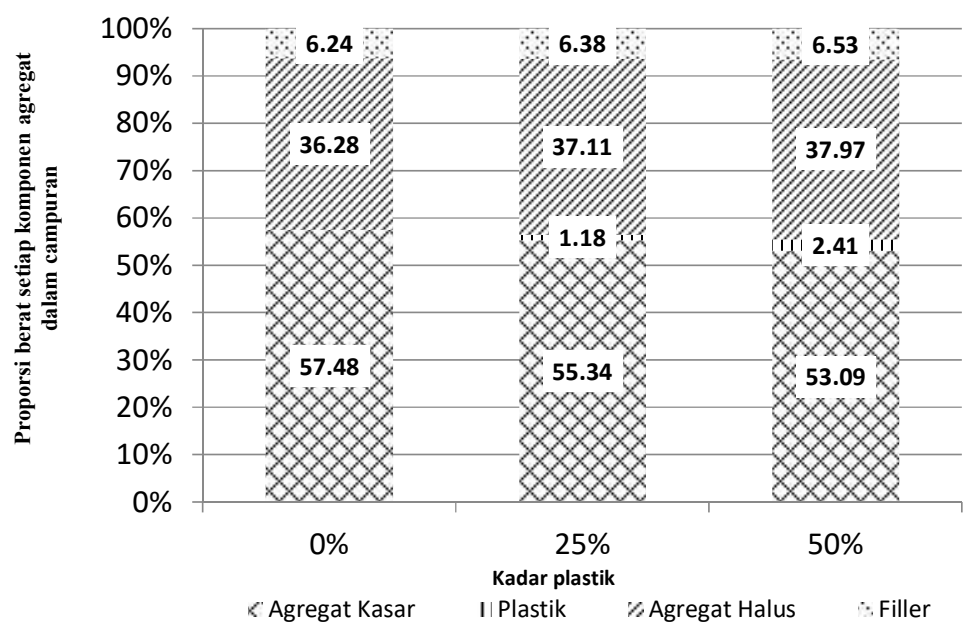

Gambar 1. Persentase komponen agregat

\section{Pengujian Rendaman Standar}

Prosedur pengujian indeks stabilitas mengikuti rujukan SNI M-58-1990. Uji perendaman dilakukan pada temperatur $60 \pm 1^{\circ} \mathrm{C}$ selama 24 jam dan selama 30 menit. Masing masing golongan terdiri dari beberapa sampel yang direndam pada bak perendaman untuk semua variasi kadar aspal. Perbandingan stabilitas yang direndam dengan stabilitas standar, dinyatakan sebagai persen, dan disebut Indeks Stabilitas Sisa (IRS), dan dihitung dengan Persamaan (1).

$$
I R S=\left[\frac{M S i}{M S S}\right] x 100 \%
$$

dengan IRS = indeks stabilitas sisa, $\mathrm{MSi}=$ stabilitas marshall perendaman $24 \mathrm{jam}, \mathrm{MSs}=$ stabilitas marshall perendaman 30 menit.

\section{Pengujian Rendaman Modifikasi}

Prosedur pengujian indeks stabilitas mengikuti rujukan SNI M-58-1990. Uji perendaman dilakukan pada temperatur $60 \pm 1^{\circ} \mathrm{C}$ selama 2 hari, 4 hari, dan 7 hari. Masing-masing golongan terdiri dari beberapa sampel yang direndam pada bak perendaman untuk semua variasi kadar 
aspal. Perhitungan Indeks Stabilitas Sisa (IRS) menggunakan rumus (1) dengan memasukkan nilai MSi sesuai dengan variasi waktu perendaman.

\section{HASIL DAN PEMBAHASAN}

\section{Bahan Campuran}

Agregat kasar, agregat halus, aspal, dan biji limbah plastik masing-masing diuji untuk memastikan setiap karakteristiknya memenuhi persyaratan yang dikeluarkan oleh Direktorat Jenderal Binamarga. Hasil pengujian tertera pada Tabel 3 dan Tabel 4.

Tabel 3. Hasil pemeriksaan fisik agregat

\begin{tabular}{|c|c|c|c|c|c|}
\hline No. & Jenis Pengujian & Spesifikasi & Hasil & Satuan & Keterangan \\
\hline \multicolumn{6}{|c|}{ Agregat Kasar } \\
\hline 1 & Abrasi dengan mesin Los Angeles & Maks 40 & 21,02 & $\%$ & Memenuhi \\
\hline 2 & Kelekatan Terhadap Aspal & Min 95 & 98 & $\%$ & Memenuhi \\
\hline 3 & Berat Jenis Semu & $\operatorname{Min} 2,5$ & 2,735 & $\mathrm{~g} / \mathrm{cm} 3$ & Memenuhi \\
\hline 4 & Absorpsi & Maks 3 & 1,76 & $\%$ & Memenuhi \\
\hline \multicolumn{6}{|c|}{ Agregat Halus } \\
\hline 1 & Absorpsi & Maks 3 & 1,15 & $\%$ & Memenuhi \\
\hline 2 & Sand Equivalent & Min 60 & 80 & $\%$ & Memenuhi \\
\hline 3 & Berat Jenis Semu & Min 2,5 & 2,763 & $\mathrm{~g} / \mathrm{cm} 3$ & Memenuhi \\
\hline \multicolumn{6}{|l|}{ Filler } \\
\hline 1 & Berat Jenis Semu & Min 2,5 & 2,747 & $\mathrm{~g} / \mathrm{cm} 3$ & Memenuhi \\
\hline \multicolumn{6}{|c|}{ Biji Limbah Plastik } \\
\hline 1 & Berat Jenis & - & 0,889 & $\mathrm{~g} / \mathrm{cm} 3$ & - \\
\hline
\end{tabular}

Tabel 4. Hasil pemeriksaan fisik aspal

\begin{tabular}{llccc}
\hline No. & Jenis Pengujian & Spesifikasi & Hasil & Keterangan \\
\hline 1 & Penetrasi pada $25^{\circ} \mathrm{C}(\mathrm{dmm})$ & $60-70$ & 67,6 & Memenuhi \\
2 & Titik lembek $\left({ }^{\circ} \mathrm{C}\right)$ & $\geq 48$ & 48,5 & Memenuhi \\
3 & Indeks penetrasi & $\geq-1$ & $\geq-1$ & Memenuhi \\
4 & Daktilitas pada $25^{\circ} \mathrm{C}(\mathrm{cm})$ & $\geq 100$ & $\geq 100$ & Memenuhi \\
5 & Titik nyala $\left({ }^{\circ} \mathrm{C}\right)$ & $\geq 232$ & 346 & Memenuhi \\
6 & Kelarutan dalam Toluene $(\%)$ & $\geq 99$ & 99,35 & Memenuhi \\
7 & Berat jenis & $\geq 1,0$ & 1,03 & Memenuhi \\
\hline
\end{tabular}

\section{Stabilitas}

Pengujian stabilitas dilakukan dengan variasi lama perendaman 30 menit, 1 hari, 2 hari, 4 hari, dan 7 hari. Nilai stabilitas masing-masing variasi plastik tercantum dalam Tabel 5, sedangkan grafik pengaruh lama perendaman terhadap nilai stabilitas ditunjukkan pada Gambar 2.

Tabel 5. Nilai stabilitas campuran

\begin{tabular}{cccc}
\hline \multirow{2}{*}{$\begin{array}{c}\text { Lama } \\
\text { Perendaman } \\
\text { (hari) }\end{array}$} & \multicolumn{3}{c}{$\begin{array}{c}\text { Stabilitas } \\
(\mathrm{kg})\end{array}$} \\
\cline { 2 - 4 } & $0 \%$ & $25 \%$ & $50 \%$ \\
\hline 0 & 1800 & 1843 & 2180 \\
\hline 1 & 1651 & 1708 & 2060 \\
\hline 2 & 1408 & 1469 & 1557 \\
\hline 4 & 1245 & 1424 & 1496 \\
\hline 7 & 1228 & 1402 & 1463 \\
\hline
\end{tabular}


Semakin panjang durasi perendaman maka nilai stabilitas akan semakin turun. Turunnya nilai stabilitas ini disebabkan terjadinya kerusakan karena pengaruh air. Kerusakan ini disebabkan oleh kegagalan kohesi, dimana air dan suhu tinggi yang mempengaruhi perkerasan akan membuat aspal melembek seiring dengan lamanya perendaman, sehingga menurunkan nilai kohesi aspal yang menyebabkan kekuatan berkurang. Turunnya nilai adhesi juga disebabkan karena pengaruh air dan durasi perendamannya. Semakin lama campuran terkena air maka akan mengakibatkan terjadinya stripping atau terpisahnya lapisan aspal dengan agregat.

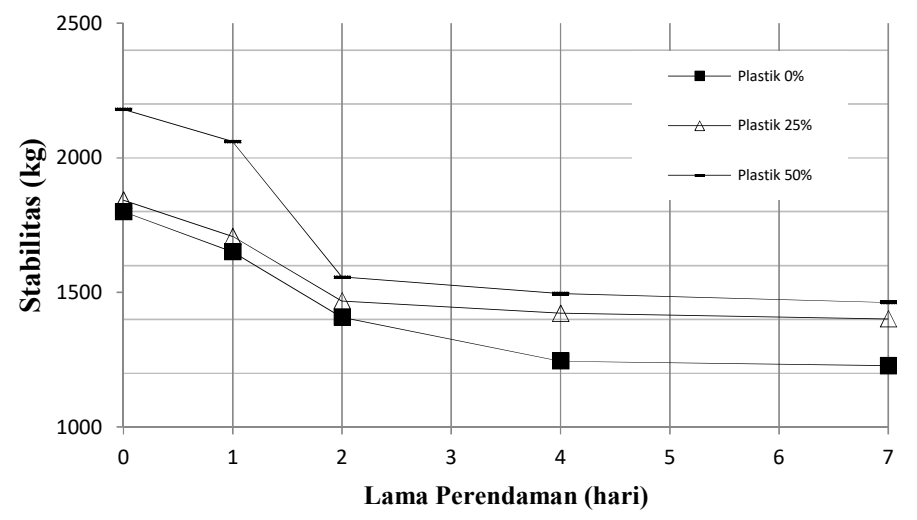

Gambar 2. Pengaruh lama perendaman dengan nilai stabilitas

Penggunaan plastik meningkatkan nilai stabilitas. Hal ini dapat terjadi karena sifat plastis dari plastik, sehingga saat pemadatan plastik akan berfungsi sebagai pengunci antar agregat. Karena agregat cukup rapat, maka stabilitas campuran meningkat. Sampai durasi perendaman selama 7 hari, stabilitas campuran dengan variasi plastik 50\% masih lebih tinggi dari stabilitas campuran dengan variasi plastik $25 \%$ dan $0 \%$, yaitu pada angka $1228 \mathrm{~kg}$.

\section{Indeks Stabilitas Sisa (IRS)}

Nilai IRS pada campuran variasi plastik $0 \%$ berturut-turut sebesar $100 \%, 91,7 \%, 78,22 \%$, $69,15 \%$, dan $68,23 \%$. Untuk campuran variasi plastik $25 \%$ berturut-turut sebesar $100 \%, 92,72 \%$, $79,74 \%, 77,26 \%$, dan 76,10\%. Sedangkan untuk campuran variasi plastik 50\%, nilai IRSnya berturut-turut sebesar 100\%, 94,5\%, 71,42\%, 68,63\%, dan 67,13\%. Grafik IRS ditunjukkan pada Gambar 3. 


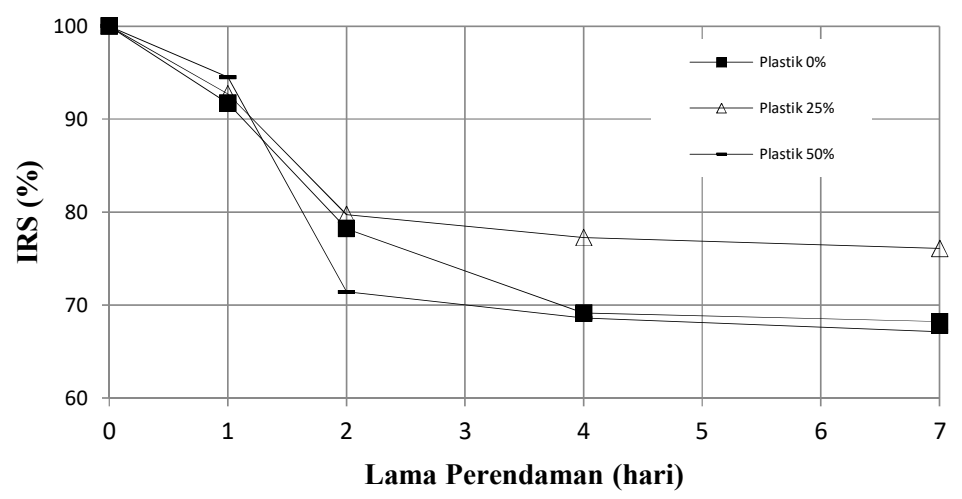

Gambar 3. Pengaruh lama perendaman dengan nilai indeks stabilitas sisa

Dapat dilihat dari Gambar 3 bahwa durasi perendaman akan mengakibatkan turunnya nilai IRS. Hal ini disebabkan karena pengaruh air akan menurunkan kekuatan ikatan antar agregat dengan aspal, sehingga nilai stabilitasnya berkurang.

Sampai akhir variasi perendaman, hanya nilai IRS pada campuran dengan variasi plastik $25 \%$ yang memenuhi persyaratan minimum $75 \%$. Sedangkan untuk campuran dengan variasi plastik $0 \%$ dan $50 \%$, besarnya nilai IRS akhir tidak memenuhi persyaratan minimum. IRS menunjukkan persen sisa kekuatan yang dimiliki oleh campuran pada variasi perendaman tertentu. Penggunaan plastik sebesar $25 \%$ pada campuran meningkatkan nilai IRS, yang berarti campuran dengan plastik 25\% mengalami kehilangan kekuatan yang lebih sedikit dibandingkan dengan campuran tanpa plastik. Hal ini juga menunjukkan bahwa penggunaan plastik $25 \%$ mengurangi kerentanan campuran terhadap pengaruh air. Ini dapat terjadi karena pada saat pemadatan, sifat plastik yang plastis akan berfungsi sebagai perekat antar agregat dan plastik akan mengurangi masuknya air rongga antara agregat dengan aspal.

Namun pada campuran dengan variasi plastik 50\%, nilai IRS menjadi paling rendah di antara variasi lainnya mulai pada perendaman 2 hari. Hal ini disebabkan karena pada awalnya, sifat plastik yang plastis akan berfungsi sebagai perekat antar agregat sehingga campuran lebih stabil, namun karena sifat thermoplastis pada plastik yang rentan terhadap suhu tinggi, perendaman dengan waktu yang lama akan menyebabkan plastik melembek sehingga sama seperti aspal, nilai kohesinya akan berkurang. Hal ini menyebabkan kekuatan campuran berkurang cepat karena campuran menjadi rentan terhadap air.

\section{KESIMPULAN DAN SARAN}

\section{Kesimpulan}

Dari penelitian yang dilakukan, dapat ditarik kesimpulan sebagai berikut:

a) Air mempengaruhi kekuatan campuran. Hal ini ditunjukkan dengan penurunan nilai stabilitas pada semua variasi penggunaan plastik, seiring dengan bertambahnya durasi perendaman.

b) Setelah lama perendaman 7 hari, nilai stabilitas terbesar didapat pada campuran dengan variasi plastik 50\%, yaitu sebesar $1463 \mathrm{~kg}$. Hal ini disebabkan karena sifat plastis dari plastik yang mengeratkan agregat.

c) Berdasarkan hasil pengujian dan analisis indeks stabilitas sisa (IRS), dapat disimpulkan bahwa durabilitas campuran $\mathrm{AC}-\mathrm{BC}$ dengan menggunakan plastik $25 \%$ menunjukkan hasil yang lebih baik dibandingkan dengan durabilitas campuran $\mathrm{AC}-\mathrm{BC}$ dengan menggunakan 
plastik 50\% dan tanpa plastik. Hal ini menunjukkan bahwa campuran dengan plastik 25\% lebih mampu menahan pengaruh rendaman dibandingkan dengan plastik 50\% dan tanpa penggunaan plastik.

d) Tingginya kekuatan campuran dengan variasi plastik 25\% ditunjukkan dengan nilai Indeks IRS yang paling tinggi diantara variasi lainnya, yaitu sebesar $76,10 \%$ pada akhir masa perendaman selama 7 hari. Hanya campuran dengan variasi plastik 25\% ini yang memenuhi persyaratan minimum IRS $75 \%$.

\section{Saran}

Saran yang dapat diberikan untuk penelitian-penelitan selanjutnya antara lain:

a) Diperlukan penelitian serupa namun dengan kadar plastik atau jenis limbah plastik yang berbeda.

b) Diperlukan penelitian mengenai pengaruh kimiawi plastik terhadap nilai stabilitas.

c) Diperlukan penelitian lebih lanjut mengenai persyaratan-persyaratan perkerasan lentur yang lainnya, sehingga keseluruhan dari hasil penelitian dapat diaplikasikan dan dijadikan gambaran untuk direalisasikan.

\section{Ucapan Terima Kasih (Acknowledgement)}

Penulis mengucapkan terima kasih kepada pihak pemberi dana (anonim) atas bantuan biaya pada penelitian ini dan kepada Departemen Teknik Sipil dan Lingkungan Universitas Gadjah Mada Yogyakarta atas kesediannya meminjamkan Laboratorium Transportasi sebagai fasilitas untuk melaksanakan penelitian ini. Penulis juga berterima kasih kepada para laboran atas bantuan teknisnya dalam penyiapan bahan uji dan pengujian.

\section{REFERENSI}

Asphalt Institute. (2001). Superpave Level 1 Mix Design. Superpave Series No. 2 (SP-2). Asphalt Institute, Kentucky.

Direktorat Jenderal Bina Marga. (2012). Spesifikasi Umum 2010-Revisi 3. Direktorat Jenderal Binamarga, Jakarta.

PlasticsEurope. (2013). Plastics-The Facts 2013 : An Analysis of European Latest Plastics Production, Demand, and Waste Data. PlasticsEurope, Belgium.

Schwartz, W.M. (1986). Ilmu Pengetahuan Populer (terjemahan) Jilid 10. Grolier International Inc, London.

Sutaryo. (2004). Pengaruh Variasi Temperatur Pemadatan Terhadap Sifat Marshall Dan Indek Stabilitas Sisa Berdasarkan Spesifikasi Baru Beton Aspal Pada Laston (AC-BC) Menggunakan Jenis Aspal Pertamina Dan Aspal Esso Penetrasi 60/70. Teknik Sipil Universitas Diponegoro, Semarang.

Tajudin, A. N. (2015). Karakteristik Durabilitas Pada Campuran Asphalt Concrete Binder Course (AC-BC) dengan Penggunaan Limbah Plastik HDPE Sebagai Agregat Pengganti. Universitas Gadjah Mada, Yogyakarta.

Hicks, R. G., Santucci, L., \& Aschenbrener, T. (2003). "Introduction and Seminar Objectives on Moisture Sensitivity of Asphalt Pavements". Transportation Research Board National Seminar, San Diego, 4 - 6 Februari 2003, 3-36. 
Tajudin, A. N. \& Suparma, L. B. (2014). "Pemanfaatan Limbah Plastik HDPE sebagai Agregat Pengganti pada Campuran Asphalt Concrete - Binder Course (AC - BC)". The 17th FSTPT International Symposium, Jember, 22 -24 Agustus 2014, 780-789

Nejad, F. M., Arabani, M., Hamedi, G. H., \& Azarhoosh, A. R. (2013). Influence of Using Polymeric Aggregate Treatment on Moisture damage in Hot Mix Asphalt. Construction and Building Materials, Vol. 47, 1523-1527.

Sumiati \& Sukarman. (2014). Pengaruh Gradasi Agregat Terhadap Nilai Karakteristik Aspal Beton (AC-BC). PILAR Jurnal Teknik Sipil, Vol.10 (No.1), 85-91.

Yilmaz, A. \& Sargin S. (2012). Water Effect on Deteriorations of Asphalt Pavements. The Online Journal of Science and Technology, Vol.2 (No. 1), 1-6 